\title{
LA PALABRA EN LA LITURGIA
}

DOI: https://doi.org/10.52039/seminarios.v57i199-200.355

JUAN JAVIER FLORES ARCAS, OSB ${ }^{1}$

INTRODUCCIÓN: UNA VISIÓN DE CONJUNTO DE LA EXHORTACIÓN APOSTÓLICA

Tanto el Sínodo de Obispos de 2008 sobre «la Palabra de Dios en la vida de la Iglesia», como la exhortación apostólica postsinodal Verbum Domini de Benedicto XVI, comparten una fuerte tensión litúrgica².

Ya el mismo título de la exhortación, Verbum Domini, tiene un significado litúrgico. Se ha escogido el texto de ls 40, 8 que, leído a la luz de $1 \mathrm{Pe} \mathrm{1,} \mathrm{24-25,}$ sirve de conclusión a las lecturas bíblicas en la edición latina del Misal Romano de Pablo VI. En efecto, el lector y el diácono anuncian después de las lecturas: Verbum Domini, y el pueblo responde: Deo gratias, o si se trata de la lectura del Evangelio: Laus tibi, Christe. Por tanto, el título de la exhortación apostólica es un texto bíblico, pero también es un texto litúrgico, lo que da idea de la importancia del nombre que se ha querido dar a la exhortación apostólica.

La exhortación está dividida en tres partes con una introducción y una conclusión: Verbum Dei, Verbum in Ecclesia y Verbum mundo. Es un esquema seguido también en otros documentos magisteriales, como por ejemplo la misma exhortación Sacramentum Caritatis y podemos decir que en él se pasa de la formulación teológica a la celebración litúrgica para acabar en la dimensión pastoral.

El documento pontificio parte de una fundamentación teológica de la Palabra de Dios, para en un segundo momento pasar a la praxis celebrativa, la cual desemboca en los problemas pastorales que, de esta manera, se iluminan con la fuerza de la teología y de la misma acción litúrgica.

\section{LA SEGUNDA PARTE DE LA EXHORTACIÓN}

Prácticamente toda la segunda parte por tanto de la Verbum Domini está dedicada al tema litúrgico. Se divide en tres capítulos o partes complementarias: la Palabra de Dios y la Iglesia, la liturgia, lugar privilegiado de la Palabra de Dios y la Palabra de Dios en la vida eclesial.

1. Rector del Pontificio Ateneo de San Anselmo de Roma, y experto del Sínodo de los Obispos sobre «La Palabra de Dios en la vida y la misión de la Iglesia».

2. J. J. FloRes ARCAS, «Dimensión litúrgica del Sínodo de Obispos sobre la Palabra de Dios», Teología y catequesis 109 (2009) 109-122. 
El primer capítulo de esta segunda parte se titula por tanto «La Palabra de Dios y la Iglesia» propone cómo la Iglesia acoge la Palabra (n. $\left.{ }^{\circ} 50\right)$. Insiste también en la contemporaneidad de Cristo en la vida de la Iglesia (.$\left.^{\circ}{ }^{51}\right)$. Son dos números importantes porque nos hacen entrar en la realidad actual. Insisten en la relación vital, contemporánea, que existe entre la Palabra de Dios, la Palabra del Padre y la Iglesia de hoy.

El segundo capítulo lleva un título muy significativo: «La liturgia, lugar privilegiado de la Palabra de Dios». Trata de las relaciones entre la Palabra de Dios y la liturgia. Es la parte que toca más directamente nuestro tema. Desde los distintos leccionarios a la homilía se hace un recorrido por todos los aspectos que tocan la celebración litúrgica de la Palabra de Dios.

El tercer capítulo trata de la Palabra de Dios en la vida eclesial y toca diversos aspectos de la pastoral, la catequesis, la formación bíblica, deteniéndose en particular en lo que podríamos llamar la lectura orante de la Palabra de Dios, es decir, la lectio divina. Los dos últimos capítulos se dedican a la «Palabra de Dios y oración mariana» (88) y «Palabra de Dios y Tierra Santa» (89).

\section{LA LitURGIA, LUGAR PRIVILEGIAdO DE LA PALABRA DE DIOS}

En el centro de la exhortación se encuentra este segundo capítulo que en algún sentido es el punto neurálgico de toda ella, además de ser su argumento central. El mismo título del mismo es ya una toma de posesión en el tema: «La liturgia, lugar privilegiado de la Palabra de Dios».

El capítulo entre los números 52 al 71 contiene nueve títulos, donde trata los siguientes argumentos: La Palabra de Dios en la Sagrada Escritura, Sagrada Escritura y sacramentos, Palabra de Dios y Eucaristía, sacramentalidad de la Palabra, Sagrada Escritura, el leccionario como proclamación de la Palabra, el ministerio del lectorado, la homilía, oportunidad de un directorio homilético, Palabra de Dios en relación con la reconciliación y unción de enfermos, Palabra de Dios y Liturgia de las Horas, Palabra de Dios y bendicional, la animación litúrgica, celebraciones de la Palabra de Dios, la Palabra de Dios y el silencio, proclamación solemne de la Palabra de Dios, la Palabra de Dios en el templo cristiano, exclusividad de los textos bíblicos en la liturgia y, finalmente, el canto litúrgico. Se detiene también en recordar la especial atención que merecen los discapacitados de la vista y el oído en nuestras celebraciones litúrgicas.

Como punto de partida, el número 52 habla de la relación entre la Palabra de Dios y la liturgia. Si la Iglesia es la «casa de la Palabra» habrá que prestar atención ante todo a la Sagrada Liturgia sabiendo que «todo acto litúrgico está por naturaleza empapado de la Sagrada Escritura». Se recuerda aquí además para ello los números 24 y 7 de la constitución de liturgia Sacrosanctum Concilium que tratan de las relaciones entre Biblia y liturgia. En este contexto es im- 
portante la clara preferencia que la exhortación hace a la presencia de Cristo en la acción litúrgica recordando los números 4,9 y 3, de la Ordenación de las lecturas de la Misa que insisten en el método que Cristo usó para la lectura e interpretación de las Sagradas Escrituras y que la Iglesia ha heredado de su fundador haciendo irrumpir la Palabra en el «hoy» de su acontecer personal. Se constata así que la hermenéutica que la fe debe hacer de la Sagrada Escritura ha de tener siempre la liturgia como punto de referencia pues en ella se celebra la Palabra de Dios como palabra viva y actual.

A partir del número 53 , el documento se detiene en las relaciones existentes entre la Sagrada Escritura y los sacramentos o la acción sacramental. El principio que pone ambos en relación está tomado de la Exhortación apostólica Sacramentum Caritatis. Se presenta así: «es más conveniente que nunca profundizar en la relación entre Palabra y Sacramento, tanto en la acción pastoral de la Iglesia como en la investigación teológica». Se insiste, citando el documento de la Pontificia Comisión Bíblica «La interpretación de la Biblia en la Iglesia», en que la liturgia de la Palabra es un elemento decisivo en la celebración de cada sacramento de la Iglesia. En este mismo número se trata el «carácter performativo de la Palabra de Dios» diciendo cómo en la historia de la salvación no hay separación entre lo que Dios dice y lo que hace, pues su Palabra se manifiesta como palabra viva y eficaz $(\mathrm{Hb} 4,12)$. En la acción litúrgica, la Palabra de Dios «realiza lo que dice». En conexión con este tema, el número 56 se refiere a la sacramentalidad de la Palabra, un tema significativo que ha surgido durante la asamblea del Sínodo y que conviene destacar por su novedad. Dicha sacramentalidad se entiende en analogía con la presencia real de Cristo bajo las especies del pan y del vino consagrados ya que Cristo, realmente presente en las especies del pan y del vino, está presente de modo análogo también en la $\mathrm{Pa}$ labra proclamada en la liturgia. De este modo lo que se pretende es «favorecer una comprensión más unitaria del misterio de la revelación en obras y palabras íntimamente ligadas, favoreciendo la vida espiritual de los fieles y la acción pastoral de la Iglesia» (ibid.).

En los números 54 al 60 se trata especialmente de la celebración eucarística y se tocan argumentos doctrinales constitutivos como son «Palabra de Dios y Eucaristía». Concretamente se pasa a estudiar todo lo referente al leccionario (57), al ministerio del lector (58) y la homilía (59-60).

Fue Mons. Ricardo Blázquez, entonces obispo de Bilbao, el primero que habló del tema de la homilía en el Sínodo de la Palabra de Dios. Siguieron algunas intervenciones más que recalcaron un tema tan importante como es el de la explicación de la Palabra proclamada en la acción litúrgica, especial pero no exclusivamente, en la Eucaristía. Se ha insistido en que la homilía debe glosar la Palabra de Dios, es decir, el leccionario bíblico. Hay que explicar de modo adecuado las lecturas proclamadas. Se pidió que las homilías fuesen bíblicas, ni moralizantes ni políticas. Por ello las homilías han de ser litúrgicas, es decir 
deben comentar el texto bíblico. Puesto que la homilía es un acto litúrgico, no moral ni doctrinal -pues existe la Palabra anunciada y la Palabra celebrada-, se pidieron que las homilías sean mistagógicas, es decir, que expliquen no sólo la Palabra de Dios, sino también el rito y la misma celebración. Esto tiene mayor importancia cuando dentro de la Eucaristía se celebra otro sacramento como el bautismo, la confirmación, el matrimonio, las ordenaciones o incluso la unción de enfermos. En estos casos caso la homilía tendría que explicar también la dinámica celebrativa de cada sacramento. En cualquier caso, no hay duda de que la Palabra de Dios debería ser la única fuente de inspiración de la homilía.

Siguiendo con el tema de la homilía, la exhortación dice que «se han de evitar homilías genéricas y abstractas, que oculten la sencillez de la Palabra de Dios, así como inútiles divagaciones que corren el riesgo de atraer la atención más sobre el predicador que sobre el corazón del mensaje evangélico. Debe quedar claro a los fieles que lo que interesa al predicador es mostrar a Cristo, que tiene que ser el centro de toda homilía» (n. $\left.{ }^{\circ} 59\right)$. En el Sínodo se ha pedido que, en relación con el Compendio eucarístico, se elabore un «Directorio sobre la homilía» de manera que los predicadores puedan encontrar en él una ayuda útil para prepararse en el ejercicio del ministerio.

Palabra de Dios y Eucaristía se compenetran. La Eucaristía, dice el número 55 de la exhortación postsinodal, nos ayuda a entender la Sagrada Escritura, así como la Sagrada Escritura, a su vez, ilumina y explica el misterio eucarístico. Palabra y Eucaristía se relacionan tan íntimamente que no se puede comprender la una sin la otra.

Pero no solo la Eucaristía se relaciona con la Palabra de Dios sino también los demás sacramentos y los sacramentales gozan de un particular nexo con la Palabra. De entre los sacramentos se hace especial mención de los llamados sacramentos de curación, como el sacramento de la reconciliación y la unción de enfermos.

Merece destacarse todo el número 62 de la exhortación, que trata la relación entre la Palabra de Dios y la Liturgia de las Horas. Citando la proposición 19, se dice cómo los padres sinodales han afirmado que ésta constituye una forma privilegiada de escuchar la Palabra de Dios. Retomando dicha proposición, el documento dice que la Liturgia de las Horas constituye una forma privilegiada de escucha de la Palabra de Dios, porque pone en contacto a los fieles con la Sagrada Escritura y con la Tradición viva de la Iglesia».

Ciertamente en la Liturgia de las Horas existe el «Oficio de lecturas», formado por salmos y lecturas bíblicas, patrísticas y hagiográficas. Hay que revalorizar este leccionario como un modo de poner en práctica cuanto propone y sugiere la exhortación Verbum Domini.

No olvida la exhortación apostólica tampoco uno de los libros más recientes de la reforma litúrgica promovida por el Concilio Vaticano II, el «Bendicional», y destaca la estrecha unión que tiene que existir entre las bendiciones litúrgicas 
y la Palabra de Dios pues la bendición, como auténtico signo sagrado «toma su pleno sentido y eficacia de la proclamación de la Palabra de Dios» (63).

La última parte de todo este capítulo dedicado a la liturgia trata de «Sugerencias y propuestas concretas para la animación litúrgica». Se insiste en un tema de gran actualidad pastoral, como son las celebraciones de la Palabra de Dios (número 65) que se recomiendan especialmente en los tiempos fuertes de Adviento y Navidad, Cuaresma y Pascua, sobre todo en las comunidades que no tienen un sacerdote que presida la Eucaristía en los días de precepto o en ocasión de peregrinaciones, fiestas importantes, misiones populares, retiros espirituales y días especiales de penitencia, reparación y perdón.

Sobre el silencio en la misma celebración litúrgica, se dice que es un modo de honrar la Palabra de Dios, puesto que el silencio es "parte de la celebración», según dice la «Ordenación general del Misal Romano» en su número 56. Prosiguiendo con esta idea, asegura que «la palabra sólo puede ser pronunciada y oída en el silencio, exterior e interior, por eso se pide que se eduque al Pueblo de Dios en el valor del silencio» (66).

Los lugares celebrativos que tienen que ver con la Palabra de Dios se mencionan en el número 68: el templo, el ambón y el altar. A este respecto, se hace notar una cuestión de gran actualidad cuando el documento papal dice que «es necesario que en los edificios sagrados se tenga siempre en cuenta la acústica, respetando las normas litúrgicas y arquitectónicas». Es interesante cómo trata la función del ambón, que «ha de colocarse en un sitio bien visible, y al que se dirija espontáneamente la atención de los fieles durante la liturgia de la Palabra». Insiste en que sea fijo, debiendo ser elemento escultórico que esté en armonía estética con el altar. De esta manera se presenta visualmente el sentido teológico de la doble mesa de la Palabra y de la Eucaristía. Además, se sugiere que el libro que contiene la Palabra de Dios tenga un sitio visible y de honor en el templo cristiano, pero sin ocupar el centro, que corresponde al sagrario con el Santísimo Sacramento (ibid.).

El número 69 recuerda que las lecturas tomadas de la Sagrada Escritura nunca sean sustituidas por otros textos. El número 70 insiste en que el canto litúrgico sea bíblicamente inspirado y, por último, en el número 71 se recuerda que hay que prestar atención a los que, por su condición particular, tienen problemas para participar activamente en la liturgia, como son las personas con discapacidad de la vista o el oído. Una sugerencia que debería tener cada vez más cabida sobre todo en las grandes celebraciones ${ }^{3}$.

La necesidad y urgencia de la formación bíblico-litúrgica es tema que subyace siempre en esta exhortación apostólica. No es posible acceder nunca a la Palabra

3. Un ejemplo a imitar: la Beatificación de Manuel Lozano Garrido (Lolo) en Linares (Jaén) el día 12 de junio de 2010. No sólo fue leída la primera lectura por un laico ciego sino que toda la celebración tuvo en cuenta perfectamente cuando ahora dice la exhortación apostólica. 
de Dios sin un buen conocimiento de la liturgia de cada día y sin una preparación previa de los textos a través de estudios y subsidios. La urgencia de la formación bíblica para una digna comprensión de las leyes de la celebración litúrgica se ha manifestado a través de diversas intervenciones durante los días del Sínodo. Por parte de los cristianos, se necesita una actitud creyente que vea en la Palabra de Dios precisamente lo que es, la voz de Dios a su pueblo.

\section{REFERENCIAS MARGINALES, PERO ILUMINADORAS}

En esta parte dedicada a la liturgia es importante ver las notas a pie de página del documento. Lo primero que se cita es el mismo Sínodo de Obispos. Entre otros pasajes se cita la llamada Relatio post disceptationem que el relator del Sínodo de obispos, cardenal Marc Ouellet, tuvo después de escuchar las intervenciones de los padres sinodales; el Mensaje final que el Sínodo hace al acabar el mismo y también las proposiciones que fueron aprobadas y con las que se elaboraron la exhortación apostólica.

Además de las citas continuas de la constitución Sacrosanctum Concilium, sobre la sagrada liturgia, a pie de página aparecen otros documentos del postconcilio que son fruto de la reforma litúrgica y que son muy significativos. Por supuesto también encuentra un lugar en ellas los demás documentos del concilio, como la Dei Verbum, o los decretos Perfectae caritatis y Presbiterorum ordinis. Siguen en importancia algunos documentos del magisterio, como el Catecismo de la Iglesia católica, el Código de derecho canónico, el Código de los cánones de las Iglesias orientales, la exhortación apostólica postsinodal Sacramentum Caritatis, el Directorio sobre la piedad popular, el Compendium Eucharisticum y la instrucción Redemptionis Sacramentum, documentos recientes de la Congregación para el Culto Divino y la Disciplina de los sacramentos, etc. De la Pontifica Comisión Bíblica se cita el documento titulado La interpretación de la Biblia en la Iglesia.

La constitución conciliar de liturgia citó ampliamente textos litúrgicos ${ }^{4}$, en cambio la exhortación Verbum Domini cita los documentos que han acompañado la reforma litúrgica, el primero de los cuales es precisamente la Ordenación de las lecturas de la Misa ${ }^{5}$, que constituye los prenotandos del leccionario ro-

4. Cf. J. PINELL, I testi liturgici di autorità nella «SC». Costituzione liturgica «Sacrosanctum Concilium». Studi a cura della Congregazione per il Culto Divino, Roma, BEL 38 (1986) 321351. "I testi liturgici, messi accanto alle citazioni bibliche, patristiche e magisteriali, assumono il carattere delle classiche voci di autorità, sulle quali poggia il ragionamento teologico. Va quindi implicitamente riconosciuta alla Liturgia la capacità di autodefinirsiı (ibid., 324).

5. Ordenación de las lecturas de la Misa. El 25 de mayo de 1969 se promulgaba la primera edición típica del Ordo Lectionum Missæ (OLM) por mandato del papa Pablo VI. Agotada ya hacía tiempo esta edición oficial de la Ordenación de las lecturas de la misa en su primera edición, la Sagrada Congregación para los Sacramentos y el Culto Divino promulgaba una segunda 
mano, y que se cita en distintas ocasiones. También se citan los prenotandos del Rito de la Penitencia y, la Ordenación general de la Liturgia de las Horas, así como las Orientaciones generales del Bendicional. Son todos documentos que han acompañado la reforma litúrgica del concilio Vaticano II y que nos dan una idea de la importancia del texto que comentamos que no sólo es fruto de su momento histórico, sino que también aprovecha todos los documentos magisteriales que han ido apareciendo recientemente lo que le da ocasión de proponer temas nuevos proyectándose así hasta el futuro.

\section{LA CELEBRACIÓN LITÚRGICA, COMO MARCO IDEAL DE LA ESCUCHA DE LA PALABRA DE DIOS}

La celebración litúrgica es el fundamento teológico de la proclamación de la Palabra de Dios, que adquiere su «marco» ideal en la celebración litúrgica, «acción sagrada por excelencia cuya eficacia, con el mismo título y en el mismo grado, no iguala ninguna otra acción de la Iglesia» ( $S C 7$ ). De igual modo, «la celebración litúrgica se convierte en una continua, plena y eficaz exposición de esta palabra de Dios» (OLM n. $\left.{ }^{\circ} 4\right)$. La economía salvífica adquiere su máxima representación y presencia en esta acción litúrgica por lo que se pasa de la Palabra revelada a la Palabra proclamada, de modo que dentro de la acción litúrgica dicha Palabra adquiere, en el marco celebrativo, la plena actuación de cuanto dice y proclama.

Podríamos, por tanto, hablar de una incidencia litúrgica de la Palabra de Dios. Ya Cipriano Vagaggini decía que los textos del Nuevo Testamento leídos hoy en la liturgia se iluminan de una luz toda propia. Esta luz, toda propia y, en cierto modo, nueva, proviene de tres fuentes: la vida de la Iglesia, la evolución o ex-

edición típica el 21 de enero de 1981 y la ha publicado por primera vez en la revista Notitiae 1981, 361-462. Esta $2^{a}$ edición de la OLM se justificaba, ante todo, por haberse agotado la primera y porque había que incorporar algunas notificaciones nuevas hechas entre 1969 y 1981. Se echaba de menos unos prenotandos semejantes a la Ordenación General del Misal Romano de 1969 o a la misma Ordenación General de la Liturgia de las Horas de 1971. En comparación con estos documentos, la Ordenación de las Lecturas de la Misa era muy pobre y contenían tan solo los principios relativos a la selección de las lecturas, algunas indicaciones sobre el leccionario de cada tiempo litúrgico y las reglas prácticas para las ediciones en lenguas modernas. Habían ido apareciendo en estos años los distintos rituales con unos prenotandos de rico contenido teológico y litúrgico que indudablemente son el mejor estudio histórico-teológico de los distintos sacramentos o sacramentales. En este sentido, el Ordo Lectionum Missæ era bastante pobre, muy corto, y sin la amplia presentación a que nos han acostumbrado los rituales, la Eucaristía y la Liturgia de las Horas. La $2^{a}$ edición típica del Ordo Lectionum Missæ es una obra nueva y distinta, en gran parte y mejora a la primera edición. La mayor aportación que ha hecho son los prenotandos. Ha habido un notable cambio y un considerable enriquecimiento de la Ordenación de las Lecturas de la Misa. La ampliación consiste en que se ha añadido un Proemio y una parte primera totalmente nueva, mientras que los Prenotandos de 1969 se han conservado sustancialmente en la segunda parte. De 25 páginas se ha pasado a 125 . Un buen estudio en lengua italiana: R. DE ZAN, «I molteplici tesori dell'unica Parola di Dio». Introduzione al Lezionario e alla lettura liturgica della Bibbia, Messagero, Padova 2008. 
plicitación de los dogmas y de las doctrinas y la situación personal del fiel que en ese momento vive hic et nunc la misma acción litúrgica ${ }^{6}$.

La Iglesia da a ciertos textos bíblicos una profundidad que no vieron los mismos apóstoles. Podemos decir claramente que esta lectura litúrgica de la Biblia es la lectura específicamente cristiana de la Escritura, siendo ésta la única lectura que agota todo el sentido que aquella tiene a los ojos de su autor principal. Siendo ésta la lectura teológica de la Biblia ${ }^{7}$.

Pongamos algunos ejemplos tomados de la aplicación de textos del Antiguo Testamento a las fiestas marianas o al mismo año litúrgico: ¿por qué en adviento se lee a Isaías y no el Éxodo, que se lee en cuaresma?, ¿por qué se lee el libro de Rut y el Cántico de los Cánticos en Navidad y, en cambio, el libro de los Hechos de los Apóstoles y el Apocalipsis en el tiempo pascual?, ¿por qué no se lee el Antiguo Testamento en el tiempo pascual?

El leccionario ofrece más ejemplos del evangelio. La Iglesia ha escogido sabiamente como evangelio para la solemnidad de la Inmaculada Concepción el relato de la Anunciación y, en cambio, ha propuesto el Magníficat para la Asunción. ¿No nos está dando así la hermenéutica de la fiesta? En este sentido, el evangelio de la solemnidad de «Todos los Santos» es el de las Bienaventuranzas, indicándonos con ello que los santos las han vivido de modo ejemplar.

Es siempre la Iglesia la que ha seleccionado los textos $\mathrm{y}$, de ese modo, ha hecho una lectura litúrgica de los mismos.

En ciertos tiempos litúrgicos se leen textos íntegros del Evangelio que ayudan a comprender la Palabra de Dios en su especificidad. Algunos ejemplos: la lectura del capítulo 6 del cuarto Evangelio durante los domingos 17 al 21 del ciclo dominical B. Sin duda, una ocasión extraordinaria para profundizar en el llamado discurso del Pan de Vida y, por tanto, para hacer una reflexión bíblica sobre la Eucaristía. Otro ejemplo lo tenemos en el año 2011 que hemos iniciado. Desde el domingo cuarto del tiempo ordinario hasta el domingo noveno, en el ciclo A, se lee íntegramente todo el Sermón de la Montaña, según el evangelio de Mateo. Son seis domingos que ayudarán a comprender mejor todo el mensaje allí contenido. Una vez más, el leccionario nos proporciona la oportunidad de entrar en los grandes contenidos del Evangelio.

El año litúrgico actualiza la Palabra de Dios en su pedagogía celebrativa y proporciona a cada fiesta, a cada ciclo, a cada período, la Palabra de Dios más conveniente y adaptada. La celebración litúrgica, por tanto, hace de marco ideal de la lectura. Hay por tanto proclamación pero también actualización de la Palabra de Dios. Se ofrece así la oportunidad de leer textos bíblicos por entero que son ocasiones de profundizar en los grandes contenidos de nuestra fe.

6. C. VAGAGGINI, El sentido teológico de la liturgia. Ensayo de liturgia teológica general, BAC 181, Madrid 1959, 443-444.

7. Ibidem, 447. 


\section{El Espíritu Santo en la escucha de la Palabra de Dios}

Las Sagradas Escrituras tienen su lugar hermenéutico en el misterio de la Iglesia porque son el don del Espíritu a la Iglesia, esposa de Cristo. La exhortación Verbum Domini insiste en el papel que tiene el Espíritu Santo en la inspiración, interpretación y comprensión de las Escrituras (n. $\left.{ }^{\circ} 15\right)$. Dicho Espíritu anima y dinamiza cada proclamación de la Palabra de Dios. «Más aún, la economía de la salvación, que la palabra de Dios no cesa de recordar y de prolongar, alcanza su más pleno significado en la acción litúrgica, de modo que la celebración litúrgica se convierte en una continua, plena y eficaz presentación de esta palabra de Dios. Así, la palabra de Dios, propuesta continuamente en la liturgia, es siempre viva y eficaz por el poder del Espíritu Santo, y manifiesta el amor activo del Padre, que nunca deja de tener eficacia para con los hombres» (OLM, n. 4).

La asamblea litúrgica, convocada y reunida por el Espíritu para escuchar la proclamación, resulta transformada por la misma acción del Espíritu que se manifiesta en la celebración. Como señala Ireneo de Lyón: «Donde está la Iglesia, allí está el Espíritu del Señor; y donde está el Espíritu de Dios, allí está también la Iglesia, así como toda gracia, y el Espíritu es la verdad» (Ireneo de Lyon, Adversus Haereses, III, 24, 1).

Escuchada la Palabra en la Iglesia orante, la asamblea pasa a ser la realización concreta de la Iglesia, puesto que es en ella donde reside el Espíritu del Señor. Gracias a sus propios recursos, la liturgia de la Palabra transforma el texto proclamado en comunidad, en texto orado eclesial, en particular, gracias al Salmo responsorial y a la aclamación aleluyática. Puesto que la asamblea pasa a ser sujeto en el que reside el Espíritu por el hecho de «orar la Palabra» en comunidad, acontece que en ella se realiza la manifestación del Espíritu. En cada uno de los orantes, constituidos en Iglesia, habita el Espíritu. Gracias a la transformación orante de la Palabra, la comunidad es colmada de gracia, el hombre experimenta la acción de Dios. La Iglesia, esposa de Cristo, recibe la prenda nupcial de su Señor: el Espíritu de la verdad, que la inspira, sostiene y acompaña.

\section{LOS LECCIONARIOS BÍBLICOS: DIFICULTADES}

Diversos padres manifestaron durante el Sínodo de la Palabra la dificultad que existe para la comprensión del Antiguo Testamento y, por tanto, de la primera lectura dominical. Otras voces manifestaron su admiración por los leccionarios bíblicos como el tesoro de la Biblia y algunas intervenciones se detuvieron en glosar la importancia que para la pastoral tienen los leccionarios dominicales, especialmente en su ciclo trienal dominical. Se pidió también la lectura total de la Biblia en la celebración litúrgica. Una intervención pidió que el Leccionario estuviera en relación con el «Catecismo de la Iglesia católica», algo que también 
se pidió en el Sínodo de la Eucaristía y sobre lo que trabaja la Congregación del Culto Divino. Otras voces pidieron una posible reforma de los leccionarios dominicales con la omisión de pasajes oscuros.

A propósito de los leccionarios, la exhortación apostólica dice concretamente que «la estructura actual, además de presentar frecuentemente los textos más importantes de la Escritura, favorece la comprensión de la unidad del plan divino, mediante la correlación entre las lecturas del Antiguo y del Nuevo Testamento, centradas en Cristo y en su misterio pascual» (n. $\left.{ }^{\circ} 57\right)$. Las dificultades se deben considerar a la luz de la lectura canónica, es decir, de la unidad intrínseca de toda la Biblia. De ahí que se sugieran subsidios que ayuden a comprender el nexo entre las lecturas propuestas por el Leccionario. En este sentido, el documento, en la primera parte $\left(n .^{\circ} 42\right)$, habla precisamente de las páginas oscuras de la Biblia, recordando que la revelación bíblica está arraigada en la historia y que la revelación se acomoda al nivel cultural y moral de épocas lejanas que el hombre de hoy debe conocer para captar el mensaje que Dios ha encarnado allí. Se dice en concreto que «hay que ser conscientes de que la lectura de estas páginas exige tener una adecuada competencia, adquirida a través de una formación que enseñe a leer los textos en su contexto histórico-literario y en la perspectiva cristiana, que tiene como clave hermenéutica completa el Evangelio y el mandamiento nuevo de Jesucristo, cumplido en el misterio pascual» (ibid.).

\section{LA IGLEsia nACE Y VIVE dE LA PALABRA DE DIOS}

Por ello, la primera actitud frente a la Palabra ha de ser la de ponerse en religiosa escucha y acogerla con una fe humilde y confiada, a imitación de María, que escucha y practica la Palabra (cf. Lc 1,38) y que por ello ha sido puesta por el Señor como modelo de la Iglesia. Dicha Palabra sostiene, penetra y anima, en la potencia del Espíritu Santo, toda la vida de la Iglesia.

Ciertamente es misión de la Iglesia proclamar a Cristo como la Palabra de Dios que se hace carne, y lo hace como respuesta continua y permanente a una exigencia y a una responsabilidad que no cesa jamás en la Iglesia. San Agustín lo expresa con palabras lapidarias: «La Eucaristía es nuestro pan cotidiano... La virtud propia de este alimento es la de producir unidad, de modo que... seamos lo que recibimos. Y de este modo también las lecturas que escucháis cada día en la Iglesia son pan cotidiano, así como escuchar y recitar himnos es pan cotidiano. Estos son las ayudas necesarias a nuestra peregrinación terrenal ${ }^{8}$. Este alimento permanente de la Iglesia la hace crecer en la peregrinación de la vida y la hace conocer mejor la voluntad de Dios.

8. Sant' Agostino, Discorsi 57, 7 (Opere di Sant'Agostino XXX/1), Roma 1982, 171-173; cf. PL 38, 389. La traducción es nuestra. 
Existe también un modo privilegiado de acceso a la Palabra de Dios que es la lectio divina, a la que se alude en diversos momentos de la exhortación apostólica (nn. 86-87).

No se olvida tampoco la dimensión ecuménica que tiene el estudio y la profundización de la Palabra de Dios y se percibe con satisfacción cómo la Biblia es hoy el mayor punto de encuentro para la oración y el diálogo entre las Iglesias y las comunidades eclesiales.

Del mismo modo, la Palabra de Dios debe de ser luz para el diálogo interreligioso, a partir del pueblo judío y con otras religiones, para acabar en que la misma Palabra de Dios es fermento de las culturas modernas.

\section{CONCLUSIÓN: LA VUELTA A LA PALABRA DE DIOS COMO IDENTIFICACIÓN DEL CRISTIANO}

No hay duda de que el Sínodo del 2008 ha sido una magnífica ocasión para profundizar en la fuerza de la Palabra de Dios en el mundo de hoy, y que la exhortación apostólica Verbum Domini está llamada a ser también un documento destacado de cara al conocimiento, difusión y comprensión de la Palabra de Dios.

Una piedad cristiana que no se alimente de la Palabra de Dios corre el riesgo de caer en el subjetivismo y en cierto devocionalismo, con el peligro de dejar de lado las fuentes de la revelación en favor de otros caminos. La vuelta, por tanto, a la Palabra de Dios como base de la espiritualidad y de la misma piedad del pueblo cristiano es el fundamento de toda la reforma litúrgica del Concilio Vaticano II, así como de otros documentos conciliares, como la constitución sobre la divina revelación Dei Verbum.

Esto es ya un primer elemento que puede producir fruto abundante. Un segundo elemento a destacar es la incidencia litúrgica de la Palabra de Dios. La Palabra de Dios se encarna continuamente en la celebración litúrgica. El binomio Biblia-liturgia es fundamental para entender cómo la Palabra de Dios llega a nosotros e ilumina al hombre de hoy.

La Biblia no es un elemento más de los componentes de la acción litúrgica, sino el elemento esencial, como dice la constitución conciliar de liturgia: «En la celebración litúrgica, la importancia de la Sagrada Escritura es sumamente grande. Pues de ella se toman las lecturas que luego se explican en la homilía, y los salmos que se cantan, las preces, oraciones e himnos litúrgicos están penetrados de su espíritu y de ella reciben su significado las acciones y los signos. Por tanto, para procurar la reforma, el progreso y la adaptación de la sagrada Liturgia, hay que fomentar aquel amor suave y vivo hacia la Sagrada Escritura que atestigua la venerable tradición de los ritos, tanto orientales como occidentales» (SC 24).

El binomio Biblia-liturgia, a lo largo de los siglos, se ha enriquecido mutuamente, de manera que se ha podido afirmar que «la liturgia es la Biblia transfor- 
mada en palabra proclamada y en palabra rezada y actuada: la liturgia es la palabra celebrada» ${ }^{9}$.

Se puede aplicar también a la Palabra de Dios cuanto la schola lacensis y Odo Casel proponía sobre el culto cristiano como actualización real de la misma obra de la redención, bajo el velo de los ritos y de los símbolos de la liturgia. Lo cual quiere decir acción concreta que hace presente una acción pasada.

La proclamación de la Palabra de Dios en la acción litúrgica produce el mismo efecto de actualización del hecho proclamado, pues reactualiza el acto salvífico que se propone en la lectura. En las lecturas «Dios habla a su pueblo» y el mismo Cristo, por su Palabra, se hace presente en medio de sus fieles. El pueblo responde con el canto y con las aclamaciones.

En su obra El Misterio pascual, Luis Bouyer comenta que la lectura del Evangelio no es, en la Iglesia, un simple recuerdo de acontecimientos pasados ya irremediablemente. Al contrario, constituye el sacramento de su presencia que se renueva indefinidamente para nosotros ${ }^{10}$.

Una de las conquistas más interesantes de la exégesis moderna, es el relieve que se ha dado a esta noción litúrgica de los evangelios, que no fueron compuestos como simples recopilaciones de recuerdos, sino como el anuncio de las realidades que la Iglesia tenía conciencia de vivir en el culto. El mismo Bouyer, en el año 1943, escribía a Duployé: «la liturgia y particularmente la liturgia romana, en su configuración, es materialmente bíblica» ${ }^{11}$.

De ahí que podamos decir que toda la liturgia católica surge de la proclamación y del anuncio de la Palabra de Dios, la cual está compuesta de lo que nos transmitieron los profetas para preparar la venida del Mesías y de cuanto los apóstoles recibieron de labios del Maestro.

Esto nos indica la alta estima en que la Iglesia tiene la Palabra de Dios. Se destaca aquí el valor que tiene en la celebración eucarística la doble mesa de la Palabra de Dios y de la Eucaristía. La Iglesia honra con la misma veneración, aunque no con el mismo culto, la Palabra de Dios y el misterio eucarístico, y quiere y sanciona que siempre y en todo lugar se imite este proceder (OLM 10).

El número 54 de la exhortación apostólica recalca la profunda unidad entre la Palabra de Dios y la Eucaristía (cf. Dei Verbum 21) tal y como se expresa en algunos textos bíblicos concretos, como Juan $6,35-58$ y Lucas $24,13-35$. De este modo se supera la dicotomía que, entre las dos realidades, a menudo existe en la reflexión teológica y en la pastoral. Dice el número 55 de la exhortación que estos dos relatos (el relato de Emaús y el discurso del Pan de Vida de Juan 6) «muestran cómo la Escritura misma ayuda a percibir su unión indisoluble con

9. R. DE ZAN, Bibbia e Liturgia, Scientia Liturgica I, Introduzione alla Liturgia, ed. A. Chupungco, 49.

10. L. BOUYER, II mistero pasquale, Libreria editrice Fiorentina, Florencia 1955, 355.

11. ID., Le métier de théologien. Entretien avec Georges Daix, Ed. France-Empire, Paris 1979, 235. 
la Eucaristía... Palabra y Eucaristía se pertenecen tan íntimamente que no se pueden comprender la una sin la otra: la Palabra de Dios se hace sacramentalmente carne en el acontecimiento eucarístico. La Eucaristía nos ayuda a entender la Sagrada Escritura, así como la Sagrada Escritura, a su vez, ilumina y explica el misterio eucarístico» (ibid.).

Ciertamente la Palabra de Dios se hace carne sacramental en el evento eucarístico y lleva a su cumplimiento y plena realización la Sagrada Escritura.

Toda la Sagrada Liturgia y, más concretamente la Eucaristía, es un principio hermenéutico de la Sagrada Escritura, así como la Sagrada Escritura ilumina y explica el misterio eucarístico y toda la acción celebrativa y litúrgica.

En este sentido se puede comprender el título que la exhortación apostólica Dei Verbum ha dado al capítulo dedicado más concretamente a la liturgia, dado que ésta es el lugar privilegiado de la Palabra de Dios.

La liturgia de la Palabra es un misterio, con estas palabras acaba su estudio sobre la liturgia de la Palabra Joseph Gelineau ${ }^{12}$. Ciertamente un misterio porque es Dios quien habla a su pueblo. La celebración litúrgica lo que se celebra es el Verbo de Dios, Cristo. Es El quien nos habla directamente, más aún quien toca a la puerta para entrar y cenar con nosotros $(A p .3,20)$.

El Espíritu actúa a favor nuestro e ilumina todo el proceso. La inteligencia de la fe puede suplir las ignorancias que tengamos de las Sagradas Escrituras.

La Iglesia sigue gozando y viviendo de este Misterio de la Palabra que se encarna en la celebración y que vive en los celebrantes.

12. J. GelineAu, La liturgia della Parola, en Nelle vostre assemblee. Teologia pastorale delle celebrazioni liturgiche, Queriniana, Brescia ${ }^{31986,184-197 . ~}$ 